\title{
Climate change, migratory species and pandemic influenza
}

\author{
K. Duncan \\ University of Toronto, Canada
}

\begin{abstract}
Environment and health dominate international journals, newspapers, and global search engines with climate change and avian flu usurping world headlines. Global mean temperature is projected to increase $1.1-6.4^{\circ} \mathrm{C}$ over the coming century, a rise greater than any increase experienced by humans during the past 10,000 years. Climate change is a growing concern to the World Health Organization (WHO) because of its potentially serious health consequences, including an increase in illness and death related to extreme temperature events, weather events, and infectious disease.

A more pressing issue for the WHO is pandemic flu, which leading influenza experts fear is inevitable, if not imminent; for example, evidence suggests that influenza A H5N1 is now endemic in parts of Asia, is affecting new mammalian hosts, is expanding its geographic range, and is increasingly pathogenic.

Future climate change is likely to impact migratory bird species, their breeding and non-breeding areas, migration routes, and stopover sites. This paper will therefore first discuss environmental controls for key migratory species, and how climate change may influence their survival and distribution, and possibly affect the spread of highly pathogenic influenza. This paper will then discuss other possible impacts of climate change on pandemic influenza.

Keywords: global climate change, pandemic influenza, migratory birds, climatic impacts.
\end{abstract}

\section{Introduction}

Global mean temperature is projected to increase $1.1-6.4^{\circ} \mathrm{C}$ over the coming century, a rise greater than any increase experienced by humans during the past 10,000 years (IPCC [1]). Climate change is a growing concern to the World 
Health Organization (WHO) because of its potentially serious health consequences, including an increase in illness and death related to extreme temperature events, weather events, and infectious disease (Duncan [2]).

A more pressing issue for the WHO is pandemic flu, which leading influenza experts fear is inevitable, if not imminent; for example, evidence suggests that influenza A H5N1 is now endemic in parts of Asia, is affecting new mammalian hosts, is expanding its geographic range, and is increasingly pathogenic (Duncan [3]). Between February, 2006, and April, 2006, 32 countries, located in Africa, Asia, Europe, and the Middle East, reported their first cases in birds. This spread marks the fastest and most extensive geographical spread of any highly pathogenic influenza virus since the disease was first described in 1878. The virus has now affected some of the world's most densely populated and impoverished regions - areas poorly served by health care and surveillance systems (Duncan [4-5]).

Future climate change is likely to impact migratory bird species, their breeding and non-breeding areas, migration routes, and stopover sites. This paper will therefore explore the environmental controls for key migratory species, and how climate change may influence their survival and distribution, and possibly affect the spread of highly pathogenic influenza.

\section{Environmental health}

Restoring health to the world's ecosystems must be an essential component in the strategy to reduce human vulnerability to emerging and re-emerging diseases (Chivian [6]); McMichael [7]; and WHO [8]). Unfortunately, environmental factors (including high concentrations of poultry production, especially in areas with high human population densities, and poultry production in major wild bird flyway zones) have, in part, given rise to the pandemic influenza threat (IISD [9]).

It is important to address the environment because the control of many infectious diseases requires an understanding of the causative agent, the vector, the host and the environment in which transmission occurs. The most pressing environmental issue facing humankind is climate change, and as a result, it warrants exploration, as does its possible impacts on the spread of influenza.

\subsection{Climate change}

According to the Intergovernmental Panel on Climate Change (IPCC)'s Fourth Assessment Report, 'warming of the climate is now unequivocal, as is now evident from observations of increases in global air temperatures, widespread melting of snow and ice, and rising global average sea level.' More disturbing is the fact that most of the observed warming is likely due to increased concentrations of GHGs (IPCC [1]).

Continued GHG emissions at or above current rates would cause further warming 'and induce changes in the global climate system that would very likely be larger than those observed during the $20^{\text {th }}$ century'. Global mean temperature 
is projected to increase $1.1-6.4^{\circ} \mathrm{C}$ over the coming century (IPCC [1]), a rise greater than any increase experienced by humans during the past 10,000 years (Houghton et al. [10-12]). Anthropogenic warming and sea level rise would continue for centuries due to the timescales associated with climate processes and feedbacks, even if GHGs were to be stabilized (IPCC [1]). Susceptibility to climate change differs across countries, populations, regions and sectors (Cohen and Miller [12] and McCarthy et al. [13]).

\section{Influenza}

Influenza, like climate change, is receiving worldwide attention, as countries, organizations, and individuals prepare to mitigate its effects. Briefly, influenza is a unique respiratory viral disease infecting the whole respiratory tract, namely, the nose, sinuses, throat, lungs, and even the middle ear. The disease is spread from person-to-person by airborne droplets produced when an infected individual coughs or sneezes. Acute symptoms of influenza, including fever, headache, shivering, muscle pain, cough, and pneumonia, are the result of the virus replicating in the respiratory tract where infected cells die and slough off (Collier and Oxford [14]).

The influenza virus exists in three forms, called A, B, and C, but only A and B cause significant disease in humans. Despite the virus's three forms, all influenza viruses look similar. They are roughly spherical particles, 80-120 nm in diameter, containing a nucleoprotein core of RNA and a lipid envelope from which two distinct forms of glycoprotein project - the rod-shaped haemagglutinin $(\mathrm{H})$ and the mushroom-shaped neuraminidase $(\mathrm{N})$. A third protein structure, called the matrix (M1) protein layer, lines the surface of the virus, and contains M2 molecules (Hill and Knowlton [15]).

Today there is no effective cure, which works against all influenza viruses. Current prevention for influenza is by annual vaccination, particularly for highrisk groups such as those with respiratory disease, heart disease, renal trouble, and diabetes (Collier and Oxford [14]). Vaccination is given by intra-muscular injection, 6-8 weeks before the influenza season. In general, most studies suggest that vaccines reduce the frequency of severe illness, "but do less to reduce the overall frequency of infection" (Collier and Oxford [14]). The closer the vaccine is in structure to the antigenic composition of the circulating strain of virus, the more effective it is. Vaccine efficacy varies greatly from about $20 \%$ to as high as $90 \%$ depending on the patient group. Protection rates of $70-90 \%$ can be achieved in young healthy adults when vaccine and epidemic strains are closely matched (Hill and Knowlton [15]).

Influenza infection can be attenuated with the use of antiviral drugs, such as oseltamivir (Tamiflu), amantadine and rimantidine. Over-the-counter medication is also available to help ease fever and sore throats, reduce coughing, unblock sinuses, etc. Unfortunately, none of these drugs has an effect on the underlying influenza infection (Hill and Knowlton [15]; and Duncan [16]). 


\subsection{Avian Influenza}

Avian influenza refers to a large group of influenza viruses that primarily affect birds. On rare occasions, these bird viruses can infect other species, including humans (Horimoto and Kawaoka [17]). An influenza pandemic occurs when a new influenza subtype emerges that has not previously circulated in humans. Avian Influenza virus H5N1, which causes cyanosis of the un-feathered skin, diarrhea, excessive lacrimation, edema of the head and face, respiratory distress, sinusitis, and even sudden death, is a strain with pandemic potential, since it might ultimately mutate into a strain that is contagious among humans (OIE $[18,19]$; and Liu et al. [20]). Once this mutation occurs, it will no longer be a bird virus - it will be a human influenza virus.

\subsubsection{Epidemiology}

The principal vectors in the spread of $\mathrm{H} 5 \mathrm{~N} 1$ are the migration of wild birds harboring the virus - H5N1 infections have been found in dead bar-headed geese (Anser indicus), brown-headed gulls (Larus brunnicephalus), great black-headed gulls (Larus ichthyaetus), great cormorants (Phalacrocorax carbo), and ruddy shelducks (Tadorna ferruginea)-, and trade in domestic poultry. From April to June, 2005, more than 6000 migratory birds, comprised mainly of the above species, died of H5N1 infection at the Qinghai Lake Nature Reserve in China's Qinghai Province. More recently, migratory ducks have been shown to be asymptomatically carrying the $\mathrm{H} 5 \mathrm{~N} 1$ virus in Hong Kong and elsewhere in China (Chen et al. [21]).

Low pathogenic avian influenza (LPAI) viruses have been isolated from at least 105 wild bird species of 26 different families. Although many wild bird species may harbor influenza viruses, birds of aquatic and wetland environments, such as the Anseriformes (particularly ducks, geese, and swans) and Charadriiformes (particularly gulls, terns, and waders) constitute the major natural LPAI virus reservoir. Anseriformes and Charadriiformes are distributed globally, except in the most arid regions of the world (Olsen et al. [22]).

When wild migratory birds mix with domestic flocks through sharing of habitat, there is an enhanced potential for genetic re-assortment of avian influenza viruses, resulting in novel genotypes, which could trigger a human influenza pandemic. Once avian influenza is established in domestic poultry, it is a highly contagious disease. Infected birds excrete virus in high concentration in their feces and in nasal and ocular discharges. Once introduced into a flock, the virus is spread from flock to flock by contaminated equipment, egg flats, feed trucks, movement of infected birds, service crews, etc. (FAO [23-25]). Airborne transmission may occur if birds are in close proximity and with appropriate air movement (OIE [18]).

3.1.1.2 Migration Migration, a common strategy for birds occupying seasonal habitats, may range from short local movements to intercontinental migrations. Migratory birds can carry pathogens, particularly those that do not significantly affect the birds' health status. Many Anseriformes and Charadriiformes are 
known to perform regular long-distance migrations, thereby potentially distributing LPAI viruses between countries or even continents.

Birds breeding in one geographic region often follow similar migratory flyways: for example, the East Asian-Australian flyway from eastern Siberia south to eastern Asia and Australia. However the major flyways are simplified models of complex ecological-behavioral relationships, and there are numerous exceptions where populations perform differently from the common patterns (Lincoln et al. [26]; and Migratory Bird Center [27]).

Migrating birds rarely fly the full distance between breeding and nonbreeding areas without stopping over and refuelling. Many species therefore aggregate at favorable stopover or wintering sites, resulting in high local densities. These sites may be important for transmission of LPAI viruses between wild and domestic birds, and between different species (Olsen et al., [22]). One gram of contaminated manure can contain enough HPAI virus to infect one million birds (IISD [9]).

Unfortunately, the understanding of the global distribution of LPAI viruses in wild bird populations is still limited despite intense surveillance studies that have been performed in Eurasia and North America (Olsen et al. [22]).

\section{Weather and migration}

Weather can influence breeding success (through chilling or starving young) foraging conditions, and necessary behaviors, such as courtship. Extreme weather events, such as droughts and prolonged freezing, can have catastrophic effects on bird populations; El Niño events, which warm the waters off the west coast of South America, cause fish populations to crash, and ultimately, adult mortality among seabirds in the Pacific.

Weather has a profound influence on bird migrations. For a first example, temperature affects the rate of pre-migratory preparation. Maintaining body temperature under cold stress reduces the energy that might be stored as fat in preparation for the migratory journey. Therefore an earlier, warmer spring accelerates the preparation, while a cooler, later spring inhibits the process, and delays species arrival. During both spring and fall migrations, the primary stimulus for departure is the wind. In the spring, the wind is from the south, and in the fall, it is from the north in North America.

Areas of high and low pressures also affect migration. During fall migration, birds flying south usually travel the day after passage of a cold front with its brisk north winds and dropping temperatures; as wind direction becomes more variable and wind velocity decreases as high pressure begins to dominate, birds stop to feed.

Soaring birds, such as eagles, hawks, ospreys, and vultures are particularly dependent on proper wind conditions for migration, as migrants soar on convective thermals that are generated by the differential heating of the Earth's surface. It is estimated that the normal pre-migratory fat load of 100 grams in a Broad-winged Hawk would be exhausted in only five days of flapping flight. But by spiraling among thermals, its stored fat would last 20 days, more than enough 
time to provide energy for its 3,000-mile journey (Lincoln et al. [26]; and Migratory Bird Center [27]).

Indirectly, weather can influence the abundance and activity of nest predators; the abundance and availability of food, which influence frequency of doublebrooding, nestling survival, and hence seasonal fecundity; settlement patterns; and synchrony of settling, which, in turn, affects local density.

\section{Climate change and migration}

Birds are affected directly by climate; for example, they tolerate only a narrow range of temperature or rainfall. Therefore climate affects where birds live. Migratory species occupy several different areas of the planet in the course of their lives, while residents are confined to a much narrower range of climatic conditions. They are also affected indirectly-for example, through the effects of climate on their habitat and food supply (Migratory Bird Center [27]).

It is difficult to separate direct and indirect effects, but in the case of North American songbirds, January temperatures and the availability of suitable habitat determine winter distribution. Therefore as winters become warmer, bird distributions are likely to change. The implications of climate change-that is, long-term shifts in average weather-on migratory bird species have only recently begun to be addressed. There is already strong evidence that animals and plants have been affected by recent climate change. Impacts include changes in breeding performance (e.g. egg size, nesting success, etc.), changes in population distribution and size, and changes in timing of migration BOU/ECSA [28]).

Many of the changes expected in birds as a result of changing climate are subtle. One of the most common changes recorded in other parts of the world is that birds start nesting earlier. In many species, the signal to lay the first egg is temperature, as it is often a good predictor of food supplies (insects) for the young. And so, if springs become warmer, birds will breed earlier. In North America, Tree Swallows breed nine days earlier today that they did 30 years ago. In Britain, some species nest as many as 18 days earlier than 30 or 40 years ago. Climate change will also profoundly affect migration, as birds must time their flights with food supplies as they pass through multiple regions. For example, in order for the Semipalmated Sandpiper to make its flight successfully, it must take off with a tail wind and at the right time in order to coincide with the availability of its food (mud-shrimps). Its nesting grounds (Arctic tundra), wintering grounds (tropical mudflats) and migration habitat (temperate mudflats) are all susceptible to the effects of rising sea level.

Climate change is causing sea levels to rise now. It is important to note that birds have been adapting to changing climates throughout their long evolutionary history, and will no doubt continue to do so. Yet current and predicted climate changes differ in two important ways from earlier, natural changes: namely, they are faster, and they are taking place in addition to additional environmental changes, such as chemical contamination and habitat loss and fragmentation (Lincoln et al. [26]; BOU/ECSA [28]; and Migratory Bird Center [27]). 


\section{Climate change and pandemic influenza}

\subsection{Climate change, migratory species, and pandemic influenza}

From the above discussion, it is abundantly clear that weather and climate profoundly affect bird migration, and likely therefore play a role in the spread of avian influenza. Fortunately, the summer and fall of 2006 were relatively 'quiet' regarding avian influenza with Africa enduring no resurgence, Europe experiencing no cases since the outbreak in Turkey, and Vietnam, a previous hot-spot for avian influenza, suffering no cases. Specialists suggest that this quiet period has resulted from public health actions, such as risk-reduction education and measures, and improved monitoring systems.

But experts caution that the H5N1 virus has not disappeared, and could, in fact, be smouldering. Scientific American reported on January $9^{\text {th }}$ that a farmer in eastern China had contracted the H5N1 virus in December - the country's first human case of avian influenza since July, and Indonesia confirmed a death and second case in 2007 (WHO [29]).

Could warm temperatures have been playing a role in the fall quiescence? Provisional temperature data chronicle 2006 as the sixth-warmest year on record since 1850. Record-breaking temperatures occurred throughout Europe, which experienced its warmest fall in 500 years. Central England, where temperature records extend back to 1659 , recorded its warmest July, September, and autumn temperatures, and Switzerland reported November and early-December temperature readings $10^{\circ} \mathrm{C}$ above normal (Met Office [30]; and Planetark [31]). Anecdotally, in North America, New York City experienced no snowfall in November and December for the first time since 1877. In December 2006, buds appeared on apple trees in Maryland, while crocuses pushed up through the ground in New Jersey, and frogs, which normally hibernate through the winter months, were emerging, thinking spring had come.

The British Royal Society for the Protection of Birds and leading experts forecast that with increasing winter warmth, some birds will not migrate, or will migrate later in the season. The events of 2006 would seem to support their predictions. In December, European birds, including ducks, robins, and thrushes, failed to fly south from Scandinavia because of mild temperatures, and swans, which usually arrive in Britain from Siberia in October, stopped for longer than average because of an ample food supply in countries such as Estonia.

Perhaps this fall's 'calm' before the proverbial storm has been linked, in part, to warmer temperatures, and fewer, shorter bird migrations (Met Office [30]; and Planetark [31]). Regardless, it has bought us time to prepare. Even though H5N1 virus has largely fallen off media radar screens, it has not done so for public health officials, who remain concerned that the virus may mutate and become easily transmissible among humans.

\subsection{Climate change, ice, and influenza}

Warming will profoundly affect Earth, causing sea level to rise, and glaciers and permafrost to melt. More immediately, the United Kingdom's Met Office 
predicts that 2007 may become the warmest year on record (Met Office [30]). Warmer temperatures could mean that bodies of victims of pandemics, such as the 1918 Spanish influenza, could float to the surface of the permafrost. These bodies could pose a potential risk.

If this seems unlikely, the possibility was a concern to American scientists as early as 1996. Scientists were concerned that victims of smallpox and Spanish influenza might float to the surface of the Earth with warming or erode out of riparian environments, as rivers cut new courses with climate change. Burying a body in permafrost is akin to storing it in a freezer, which perfectly preserves food, and does not allow for decomposition. Permafrost might preserve the body and the virus - and perhaps serve as a source of infection (Duncan [16]).

But ice, and particularly lake ice, may also pose a risk. Migratory birds fly south in the fall, visiting lakes along their paths, and shed influenza virus into the water. In winter, the lakes freeze, and thus preserve influenza A virus for months, years, and perhaps much longer; microbes encased in glacial ice have been shown to be viable for hundreds of thousands of years. In spring, thawing releases trapped, current and past virus into the water - and perhaps may explain the re-emergence of past influenza A viruses decades after their initial emergence.

In the short term, warm winters may delay annual bird migration, and the spread of seasonal/pandemic influenza. And in the long term, warmer temperatures may thaw bodies/ice, and release current/past strains of influenza virus.

\section{$7 \quad$ Summary and challenges}

The information presented here highlights the need to scientifically test the linkages between climate change and influenza. Scientific study requires overcoming methodological challenges. For example, which climatic variables should be used, as migratory birds are exposed to a range of weather systems during their annual cycle? Should local weather variables or large-scale weather patterns be used? Which measures of migration should be used-first arrival dates/last dates, fitness and population consequences of migration? Can researchers undertake meta-analyses demonstrating why some species respond strongly to climate change and others do not?

\section{References}

[1] IPCC. 2007. Climate change 2007: the physical basis. Summary for policymakers. http://www.ipcc.ch. 26/02/07.

[2] Duncan, K. 2006 a. Climate change, health, and women. Climate Change and Health Impacts Atlantic Conference 2006. St. John's, Newfoundland and Labrador, March 23-24, 2006.

[3] Duncan, K. 2006 b. Forewarned is forearmed. The 2006 Conference Board of Canada CSR Conference. Toronto, Canada, May 17, 2006. 
[4] Duncan, K. 2006 c. Pandemic flu: current threat and call for ethics. Management Ethics. Spring, 2006.

[5] Duncan, K. 2006 d. Ethics Still Un-Addressed In Pandemic Preparedness: Possible Planning Guidelines. Management Ethics, Fall, 2006.

[6] Chivian, E. 1993. Critical Condition: Human Health and the Environment. MIT Press.

[7] McMichael, A. 2005. Modern life has brought humans and microbes closer than ever before. The Sydney Morning Herald, October 17, 2005.

[8] WHO. 2005. Human health under threat from ecosystem degradation. Media release. December 92005.

[9] IISD. 2006. Scientific seminar on avian influenza, the environment, and migratory birds. http://www.iisd.ca/ymb/ais/ymbvol123numle.html. 9/01/07.

[10] Houghton, J., Filho, L., Callender, B. et al. 1995. Climate Change 1995: The Science of Climate Change. Contribution of Working Group 1 to the Second Assessment Report of the Intergovernmental Panel on Climate Change (IPCC). Cambridge University Press.

[11] Houghton, J., Ding, Y., Griggs, D. et al. (eds). 2001. Climate Change 2001: The Scientific Basis. Contribution of Working Group 1 to the Third Assessment Report of the Intergovernmental Panel on Climate Change (IPCC). Cambridge University Press.

[12] Cohen, S. and Miller, K. 2001. North America. In: McCarthy, J., Canziani, O., Leary, N. et al. Climate Change 2001: Impacts, Adaptation, and Vulnerability. Contribution of Working Group 11 to the Third Assessment Report of the Intergovernmental Panel on Climate Change (IPCC). Cambridge University Press.

[13] McCarthy, J., Canziani, O., Leary, N. et al. 2001. Climate Change 2001: Impacts, Adaptation, and Vulnerability. Contribution of Working Group 11 to the Third Assessment Report of the Intergovernmental Panel on Climate Change (IPCC). Cambridge University Press.

[14] Collier, L. and Oxford, J. 1996. Human Virology: A Text for Students of Medicine, Dentistry, and Microbiology. Oxford University Press.

[15] Hill and Knowlton, 1998. The 1918 Project. Hill and Knowlton.

[16] Duncan, K. 2003. Hunting the 1918 Flu: One Scientist's Search for a Killer Virus. University of Toronto Press.

[17] Horimoto, T. and Kawaoka, Y. 2001. Pandemic threat posed by avian influenza A viruses. Clinical Microbiological Review 14(1):129-49.

[18] OIE. 2004. Highly pathogenic avian influenza. International Health Code. Chap 2.7.12. 2004 Manual of Diagnostic Tests and Vaccines for Terrestrial Animals. Avian influenza. http://www.oie.int/eng/normes /MMANUAL/A_00037.htm. 30/12/06.

[19] OIE. 2006. Highly pathogenic avian influenza. http://www.oie.int/eng /maladies/fiches/a_A150.htm. 30/12/06.

[20] Liu, J., Xiao, H., Lei, F. et al. 2005. Highly pathogenic H5N1 influenza virus infection in migratory birds. Science 2005 Aug 19; 309(5738):1206. 
[21] Chen, H., Smith, G., Zhang, S. et al. 2005. Avian flu: H5N1 virus outbreak in migratory waterfowl. Nature Jul 14; 436(7048):191-2.

[22] Olsen, B., Munster, V., Wallensten, A. et al. 2006. Global patterns of influenza A virus in wild birds. Science 2006 Apr 12; 312:384-8.

[23] FAO/OIE/WHO. 2004. Joint warning: domestic ducks could pose a new Avian influenza threat. Nov 11, 2004.

[24] FAO. 2005. Wild birds expected to spread bird flu virus further. FAO news release. August 31, 2005.

[25] FAO. 2006. FAO and IOE International Scientific Conference on Avian Influenza and Wild Birds. http://www.fao.org/ag/againfo /subjects/en/health/diseases-cards/conference/index_en.html. 8/01/07.

[26] Lincoln, F., Peterson, S., and Zimmerman, J. 1998. Migration of birds. U.S. Department of the Interior, U.S. Fish and Wildlife Service, Washington, D.C. Circular 16. Jamestown, ND: Northern Prairie Wildlife Research Center Online. http://www.npwrc.usgs.gov/resource/birds /migratio/index.htm. 10/01/07.

[27] Migratory Bird Center. 2006. The effect of climate change on migratory birds. http://nationalzoo.si.edu/Conservationandscience/Migratorybirds /Research/Climate_Change/default.cfm. 05/01/07.

[28] BOU/ECSA. 2002. Conference Report: Climate Change and Coastal Birds. A joint BOU/ECSA (Estuarine and Coastal Studies Association) conference, University of Hull, 22-24 March 2002.

[29] WHO. 2007. Cumulative number of confirmed human cases of Avian Influenza $\mathrm{A} /(\mathrm{H} 5 \mathrm{~N} 1)$ reported to WHO. http://www.who.int/csr/disease /avian_influenza/country/cases_table_2007_02_19/en/index.html. 23/02/07.

[30] Met Office. 2006. World weather impacts. Warmth delays bird migrations. $\quad$ http://www.metoffice.gov.uk/weather/impacts/200612 /18016131.html. 05/01/07.

[31] Planetark. 2006. Warm winter keeps migrating birds at home. Some European birds delay migration due to warmth. Planetark.org, Dec. 20, 2006. http://www.heatisonline.org/contentserver/objecthandlers /index.cfm?id=6193\&method=full. 30/12/06. 